\title{
PROFESSORES DE MATEMÁTICA DA EJA: UM ESTUDO SOBRE SUAS PRÁTICAS NÃO LETIVAS
}

Andréa Thees

Universidade Federal do Rio de Janeiro

\section{Resumo}

Este trabalho representa um recorte de uma pesquisa de Mestrado que consistiu em investigar como são desenvolvidas as práticas profissionais de professores de matemática que lecionam na EJA. Neste artigo apresento as práticas não letivas: de formação e na instituição. Por meio de um estudo de caso do cotidiano de três professores de matemática que lecionam para pessoas jovens e adultas, desenvolveu-se uma pesquisa qualitativa, cujos instrumentos investigativos foram as observações de campo, as entrevistas semiestruturadas e a aplicação de questionários. O estudo indicou que existe uma deficiência na formação inicial e continuada do professor de matemática para lecionar na EJA. Na instituição escolar, a falta de colaboração caracteriza uma postura profissional marcada pelo individualismo. Nas práticas não letivas na instituição sobressai uma atitude desinteressada, com professores que desconhecem as leis e regulamentações referentes à modalidade em que lecionam, cumprindo apenas as regras e exigências do sistema educacional.

Palavras-chave: educação matemática; práticas não letivas; educação de jovens e adultos 


\title{
MATHEMATICS TEACHERS OF ADULT EDUCATION: STUDY ABOUT THEIR NON- PEDAGOGICAL PRACTICES
}

\begin{abstract}
This work is an excerpt from a Masters research that investigated how the professional practices of mathematics teachers in Adult Education (AE) are developed. In this article I will present the non-pedagogical practices: about formation and at the school institution. By a case study of the daily routines of three mathematics teachers of $\mathrm{AE}$, a qualitative research was developed, employing these investigation tools: field observation, semi-structured interviews and questionnaires. This study indicated a shortcoming during the graduation and in the continuous development of the mathematics teachers in the AE. In the school institution, the lack of collaboration characterizes an individualistic work. In the field of non-pedagogical practices, teachers displayed a non-committed attitude, unaware of laws and regulation regarding $\mathrm{AE}$, simply following rules and demands from the educational system.
\end{abstract}

Keywords: Mathematics Education; adult education; professional practice 


\section{Introdução}

O debate sobre as práticas de professores de matemática da EJA vem ocupando cada vez mais lugar de destaque, tendo em vista a quantidade de publicações, grupos de pesquisas e de trabalho, congressos e seminários sobre a temática. De fato, as práticas letivas influenciam diretamente na relação de ensino-aprendizagem que se estabelece entre professores e alunos. Entretanto, a docência não se resume apenas às situações que decorrem da sala de aula ou do trabalho realizado com e para os alunos. O professor também desempenha outros papéis que estão inteiramente relacionados às suas práticas profissionais.

Apesar de influenciarem diretamente as práticas letivas, as práticas não letivas parecem ser preteridas nas pesquisas e investigações sobre práticas profissionais. A carência de estudos, constatada a partir de uma rápida consulta às principais publicações de educação e educação matemática, juntamente com a relevância da temática para a área, motivaram alguns questionamentos: quais práticas profissionais são consideradas não letivas e por quê? Como os professores de Matemática da EJA estão desenvolvendo suas práticas não letivas? De que maneira as práticas não letivas influenciam as práticas letivas?

Considerando o ineditismo de alguns dos resultados de uma pesquisa de mestrado sobre as práticas profissionais de professores de matemática da EJA, optei por recortar este trabalho, limitando-o às práticas não letivas. Desta forma, apresentarei os resultados obtidos com o objetivo de analisar como são constituídas as práticas não letivas de professores de matemática de jovens e adultos.

Iniciarei conceituando o termo práticas profissionais de professores e seus desdobramentos, segundo o referencial de Ponte e Serrazina (2004), Ponte (2011) e Ponte, Quaresma e Branco (2008), apresentando uma síntese do que dizem as pesquisas sobre práticas não letivas de professores de matemática da EJA. Em seguida, Olh@res, Guarulhos, v. 2, n. 2, p. 449-470. Dezembro, 2014. 
descreverei brevemente os procedimentos metodológicos adotados na investigação. Depois, prosseguirei o artigo trazendo os resultados obtidos, dentro do recorte proposto. Ao finalizar, buscarei evidenciar a influência das práticas não letivas no compromisso ético e político em relação à EJA, bem como a intenção de contribuir no processo de mudança qualitativa.

\section{Equacionando a investigação}

Como em Ponte e Serrazina (2004), Ponte (2011) e Ponte, Quaresma e Branco (2008) entendo que a expressão práticas profissionais de professores refere-se às ações realizadas pelos professores nos momentos em que atuam em função da profissão de professor e não somente quando estão lecionando. As distinções sugeridas pelos autores auxiliam também na categorização das práticas letivas e não letivas. Enquanto as primeiras dizem respeito mais diretamente à relação de ensino aprendizagem, estando os alunos envolvidos diretamente ou indiretamente, as outras se relacionam a diferentes ações dos professores.

Por exemplo, integram o grupo de práticas não letivas, as práticas de formação inicial, continuada, autoformação e a colaboração em projetos e grupos, ou seja, o modo como professor atua em relação ao seu desenvolvimento profissional. As práticas não letivas na instituição referem-se à participação do professor em reuniões, ao conhecimento da legislação e regulamentos, à relação com o órgão oficial ou com o empregador e responsabilidades afins, aos movimentos associativose à participação em pesquisas. Todas estas práticas fazem parte da profissão docente e não existem isoladamente das práticas letivas (PONTE e SERRAZINA, 2004).

$\mathrm{O}$ esquema a seguir foi elaborado com o objetivo de apresentar a conceituação de Ponte e Serrazina (2004) e Ponte (2011) para práticas profissionais e procura ilustrar as distinções entre as práticas letivas das práticas não letivas dos professores. 


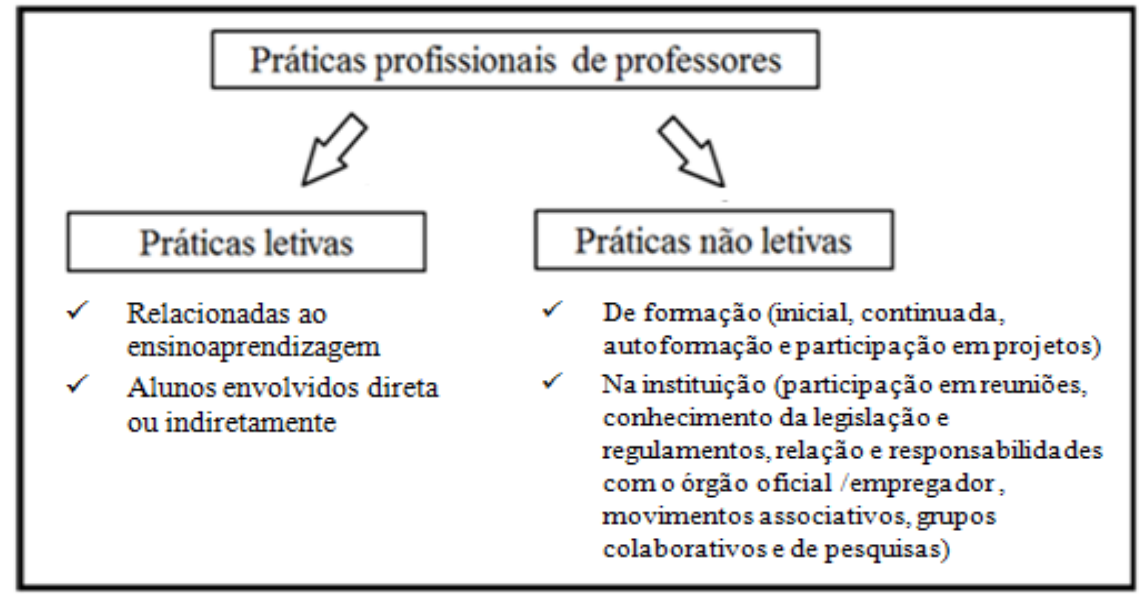

Figura 1 - Esquema das práticas profissionais letivas e não letivas

As pesquisas sobre educação de jovens e adultos vêm se desenvolvendo com bastante amplitude, buscando abarcar diferentes temáticas. No entanto, como neste trabalho o foco é investigar o desenvolvimento das práticas não letivas dos professores de matemática, convergi esta revisão de literatura aos estudos destes campos, priorizando as práticas de formação e colaboração.

Para um verdadeiro movimento em prol da sua formação, os professores necessitam ter "a consciência do mundo e a consciência de si como ser inacabado" (FREIRE, 1996, p. 57). Em outras palavras, a contínua ação de busca é consequência da certeza de inconclusão. Seria uma contradição se, sabendo-se inacabado, o ser humano não participasse de tal movimento. Entendida como uma prática profissional de caráter ininterrupto, a formação inicial, continuada e autoformação do professor, fundamenta-se na ideia freiriana de que é aprendendo que percebemos ser possível ensinar.

Algumas pesquisas sobre formação docente (BRUNELLI e DARSIE，2011; GILS，2010; COROA，2006; LOPES， 2009) indicaram que, mesmo com a crescente visibilidade em termos de EJA, ainda existe uma deficiência na formação inicial e continuada de professores de matemática no que se refere a uma formação específica para atuarem na EJA. Nesse sentido, Fantinato et al. (2011, p. 7) acreditam que a formação dos professores de matemática da EJA, 
deveria se aproximar de alguns autores das ciências sociais como uma forma de humanizar o ensino de matemática, em conexão com as propostas da etnomatemática.

Já os processos de formação continuada são vistos por Brunelli e Darsie (2011) como uma alternativa para sanar possíveis falhas ocorridas durante a licenciatura em matemática. Gils (2010) considera pertinente a formação docente continuada nas perspectivas da educação popular e da etnomatemática visando diminuir o descompasso entre a formação inicial e a atuação docente em turmas de jovens e adultos. Esta falta de engajamento na atuação profissional decorrente da deficiência na formação inicial, induz os professores de matemática da EJA a desenvolver seu trabalho quase que totalmente sozinhos, com muito pouca ou nenhuma orientação dos órgãos competentes, ou de cursos de formação continuada. Nesta direção aponta também o trabalho de Coroa (2006):

A formação inicial deficiente do professor leva também a um problema sério dentro das escolas que é a falta de um Projeto Político Pedagógico. Como não temos uma formação inicial adequada e preocupada com o trabalho que o professor vai exercer em sala de aula, não percebemos a preocupação dos professores com 0 envolvimento em projetos dentro das escolas. Isso tem levado os professores a trabalharem de forma isolada, o que consideramos prejudicial aos alunos e ao desenvolvimento profissional dos próprios professores. Consideramos que o governo precisa tomar mais decisões institucionais (...). (COROA, 2006, p. 97)

Outro resultado semelhante apareceu na pesquisa de Lopes (2009). Segundo o autor, a formação continuada dos decentes da EJA, quando há, não atende às suas necessidades e expectativas, levando os professores a construir seus saberes de modo solitário. De modo intencional, toda iniciativa de formação continuada precisaria desenvolver estratégias que favoreçam a colaboração como uma prática construída pelos integrantes de um grupo. A pesquisa de Fiorentini (2011) levantou indícios de que o trabalho colaborativo seja fundamental para o desenvolvimento profissional dos professores, desde que visto como um espaço de construção de saberes.

Olh@res, Guarulhos, v. 2, n. 2, p. 449-470. Dezembro, 2014. 
Independentemente da distinção proposta por Ponte (2011), as práticas de formação inicial, continuada, de autoformação e de colaboração de professores de matemática se entrelaçam nas ações cotidianas escolares, sofrem interferências umas das outras e passam, assim, a influenciar diretamente a atuação do professor no contexto escolar. Frente ao quadro inquietante em termos de educação no Brasil, os resultados destas investigações criam possibilidades de compreensão, análise e discussão das práticas não letivas de professores em contextos educacionais, em especial, naqueles voltados à educação matemática de jovens e adultos.

No que se refere à metodologia da pesquisa, optei pela abordagem qualitativa, conforme propõem Lüdke e André (1986) e escolhi o estudo de caso, segundo a definição de Bogdan e Biklen (1994). Para a realização da pesquisa, foi escolhida uma instituição escolar da rede pública de ensino do Estado do Rio de Janeiro, com turmas de educação de jovens e adultos. Garantidas as autorizações oficiais, iniciaram-se as observações das aulas dos três professores de matemática lotados nesta instituição, os quais concordaram em participar, e durante quatro meses diariamente, estive em campo observando suas práticas docentes das dezenove horas às vinte e duas horas.

Alguns assuntos observados durante as aulas foram categorizados e aprofundados por meio de entrevistas individuais semiestruturadas. Além dessas duas formas de coleta de dados, verifiquei a necessidade de aprofundar alguns tópicos através da aplicação de um questionário que foi respondido pelos três sujeitos da pesquisa. Sendo assim, as questões norteadoras desta investigação sobre práticas não letivas dos professores de matemática da EJA foram sendo respondidas ao longo do processo de análise dos dados, coletados por meio desses diferentes instrumentos.

Práticas não letivas dos professores Eva, Mara e Jair ${ }^{1}$

\footnotetext{
Nomes fictícios.

Olh@res, Guarulhos, v. 2, n. 2, p. 449-470. Dezembro, 2014.
} 
Os sujeitos desta pesquisa foram os professores Eva, Mara e Jair, então com 49 anos, 56 anos e 57 anos. Os professores lecionavam Matemática na educação de jovens e adultos, nas turmas de terceiro e quarto ciclo, equivalentes ao Ensino Fundamental II e no Ensino Médio. Os sujeitos, que solicitaram não serem identificados, haviam se graduado em Matemática com licenciatura plena e, na época da pesquisa, em 2011, informaram lecionar há doze anos, vinte e um anos e cinco anos, respectivamente.

As práticas não letivas dos professores de matemática, segundo Ponte e Serrazina (2004, p. 2) se relacionam de forma menos direta com o ensino aprendizagem dos alunos. Os autores sugerem organizálas em práticas de formação e práticas na instituição, e afirmam que ambas não existem isoladamente das outras práticas letivas. Em uma interpretação pessoal, conceituei como práticas não letivas as ações relacionadas com assuntos de fora da sala de aula realizadas pelo professor tendo em vista atingir certos objetivos, sem ter a intenção de lecionar algo diretamente aos educandos.

\section{Práticas de formação}

Em relação às práticas de formação, os professores Mara e Jair confirmaram, durante as entrevistas e ao responderem os questionários, que não receberam formação específica para lecionar na EJA. A professora Eva alegou que "os cursos de formação continuada que participei são muito distantes da realidade da EJA". Como foi identificado durante as entrevistas, após a formação inicial, os três professores pesquisados cursaram pós-graduação em áreas diferentes da EJA. Consequentemente, a lacuna deixada pela ausência de formação como educadores de jovens e adultos pode levar à inadequação de algumas de suas práticas docentes. Para Fonseca (2005, p. 55), "existem três dimensões, absolutamente solidárias, que devem fazer parte da formação do educador matemático de jovens e adultos". São elas:

Olh@res, Guarulhos, v. 2, n. 2, p. 449-470. Dezembro, 2014. 
- Sua intimidade com a matemática, não apenas no que se refere à ampliar ou transformar conhecimentos matemáticos e significados construídos pelo educador, mas para possibilitar uma visão mais flexível que o habilite a reconhecer, respeitar e trabalhar as contribuições e demandas dos seus alunos;

- Sua sensibilidade para as preocupações, as necessidades, o ritmo, os anseios da vida adulta, desenvolvendo no educador a disposição de abrir-se à experiência do outro, acolhendo-o, e de refletir sobre a sua prática pedagógica exercitando-se na compreensão do ponto de vista que esse aluno pode construir;

- Sua consciência política, o papel ético e político da ação educativa desenvolvida pelo educador, capacitando-o a compreender a EJA como um direito do cidadão, uma necessidade da sociedade e uma possibilidade de realização da pessoa como sujeito do conhecimento. (FONSECA, 2005, p. 55-64)

A carência na formação docente levou a professora Mara a acreditar que não existem implicações concretas acarretadas pela falta de preparo para lecionar da EJA. Mara considerou conseguir adequar sua prática docente ao aluno da EJA, pois procurou sempre "explicar tudo muito bem detalhado, com palavras de fácil compreensão ao vocabulário deles, facilitando a aprendizagem”. Jair concordou que não foi preparado para ensinar, mas que apenas "aprendeu e se aperfeiçoou na matéria" e colocou em uso "o processo da compreensão e da paciência”. O professor justificou sua estratégia da “compreensão, já que alguns demoram muito para reagir ao ensinamento e da paciência para procurar ajudá-los o máximo possível inclusive repetindo diversas vezes o conteúdo dado".

Eva tem consciência da dificuldade em "adequar o currículo mínimo ao nível variado das turmas". No seu entendimento, sua inexperiência inicial e a falta de orientação a fizeram perceber que a melhor alternativa para adequar sua prática docente ao aluno da EJA seria "criar vínculos e caminhar junto com meus alunos".

Uma formação inicial deficiente aliada à ausência de uma formação continuada ou incompatível com as demandas da EJA coloca os professores em uma situação de despreparo para lecionar nessa modalidade. Percebi em suas falas a crença de que a formação profissional ocorre no dia-a-dia, na prática, quando na verdade estes

Olh@res, Guarulhos, v. 2, n. 2, p. 449-470. Dezembro, 2014. 
professores passam ano após ano reproduzindo, com seus educandos jovens e adultos, suas ineficientes e inadequadas práticas letivas.

Respaldados pela lei, caberia aos professores da EJA procurar participar de cursos de formação continuada visando aperfeiçoar suas práticas letivas, buscando uma formação "que os habilite a participar da educação matemática de seus alunos e de suas alunas, pessoas jovens e adultas, com a honestidade, o compromisso e o entusiasmo que essa tarefa exige" (FONSECA, 2005, p. 55). A autora ainda recomenda que

a formação dos educadores de jovens e adultos deverá contribuir para uma compreensão amadurecida da mudança de perspectiva que representa passar da preocupação com o que é que dá prá ensina de Matemática numa escola para jovens e adultos para a busca da inserção do ensino da Matemática na Educação Fundamental de pessoas jovens e adultas ${ }^{2}$. (FONSECA, 2005, p. 71).

O problema começa imediatamente a seguir, pois com uma jornada de trabalho tripla, tendo que lecionar nos turno da manhã, tarde e noite para garantir uma remuneração razoável, os professores não têm disponibilidade de tempo para participar dos cursos de formação continuada. Mesmo quando conseguem adaptar o próprio horário de trabalho para conseguir frequentar um desses cursos oferecidos pela secretaria de educação, podem faltar vagas e a inscrição do professor ser recusada.

Esta questão foi revelada pela professora Eva durante uma das nossas conversas informais, entre uma aula e outra, enquanto caminhávamos pelo corredor do colégio. Com a conversa fluindo meio sem rumo, perguntei sobre o curso oferecido pela SEEDUC para professores de matemática da EJA, no qual ela havia se inscrito semanas antes. Quando me falou sobre o curso, Eva comentou que a ementa proposta no programa continha temas interessantes e ela estava empolgada para começar logo. Ironizando a situação, mas aparentando estar realmente decepcionada, Eva contou que "o curso começou sim, eu é que não fui aceita”. Para ela, o pior nem era não ter "conseguido uma vaga". O motivo daquela decepção era ela estar se

${ }^{2}$ Grifos da autora.

Olh@res, Guarulhos, v. 2, n. 2, p. 449-470. Dezembro, 2014. 
sentindo ignorada pela "organização do curso que nem ao menos enviou um comunicado explicando porque recusaram a minha inscrição ou informando a data do próximo curso". "Acho isso uma tremenda falta de consideração", concluiu.

Constatei, através deste relato, que os professores acabavam construindo seus saberes individualmente devido à escassez de oferta de vagas em cursos de formação continuada para os docentes da EJA, conforme afirma Lopes (2009). Este tratamento dispensado à iniciativa de uma professora da rede pública de ensino atenta às necessidades de investir na sua formação continuada, reforça ainda mais a concepção de docência como um percurso solitário.

Além das demandas explicitadas aqui, a formação de educadores de jovens e adultos implica em revisitar diversas questões importantes, dentre elas a noção do tratamento legal destinado a esta modalidade. A falta de conhecimento da legislação em vigor pode acarretar alguns equívocos que certamente obstruirão um entendimento da EJA na íntegra. Para exemplificar, lembrei-me de um trecho durante a entrevista da professora Eva, no qual ela afirmou não ter percebido nenhuma mudança concreta a partir da vigência do Parecer CNE/CEB 11/2000 (BRASIL, 2000) e da implementação das suas resoluções:

\footnotetext{
Pesquisadora: - Mas já era EJA ou ainda era considerado supletivo?

Professora Eva: - Não sei qual é a diferença. Qual é a diferença do EJA para o supletivo?

Pesquisadora: - A EJA tem uma legislação própria e é reconhecida como uma modalidade de ensino, exatamente para acabar com essa noção de suplência... Professora Eva: - Mas é a mesma estrutura. Eu trabalho aqui há 12 anos. Há 12 anos é a mesma estrutura. No começo nem tinha (ensino) médio, era só o supletivo...
}

O Parecer CNE/CEB 11/2000 (BRASIL, 2000), que se ocupa das Diretrizes Curriculares Nacionais para a Educação de Jovens e Adultos, assegura que "desaparece a noção de Ensino Supletivo existente na Lei $n^{\circ} 5.692 / 71 " 3$. Arroyo (2007, p. 27) confirma essa visão e denuncia que "sem alargar essa estreita visão do direito à

${ }^{3}$ Grifos do autor.

Olh@res, Guarulhos, v. 2, n. 2, p. 449-470. Dezembro, 2014. 
educação não sairemos do mesmo lugar: a EJA continuará um tempo de suplência. Ultimamente os termos suplência, supletivo, vão sendo abandonados, porém a lógica continua a mesma".

A ausência de conhecimento por parte dos professores pesquisados em relação aos documentos oficiais, não se restringia ao Parecer 11/2000. Um dos temas abordados durante as entrevistas realizadas com os professores deste estudo de caso foi a questão do currículo de matemática sugerido oficialmente para a EJA. Eva, Mara e Jair desconheciam a Proposta Curricular para a Educação de Jovens e Adultos $^{4}$ (BRASIL, 2002a, 2002b). Eva lembrou que, no início de 2011, ouviu falar numa tentativa de estruturação curricular para a EJA, mas que não havia se concretizado.

Na EJA eles estão estruturando, mas... Foi até complicado fazer um planejamento pra esse ano. Falaram que iam impor (o currículo mínimo) na EJA, mas não... Ficou a coisa meio mal-ajambrada, né? Eu até pesquisei no site da Secretaria de Educação o que eles sugeriam, mas achei nada pra EJA...

Por esta razão, os professores elaboravam o planejamento de matemática para a EJA priorizando os conteúdos que eles mesmos consideram "absolutamente indispensáveis e básicos para o período seguinte". As propostas curriculares nacionais foram elaboradas, segundo Ventura (2008, p. 125), como sugestão ${ }^{5}$ para os sistemas de ensino. Contudo, apesar de serem mecanismos criados com funções meramente regulatórias, deveriam ser conhecidas para então serem ou não criticadas.

Esta proposta curricular está inserida numa política educacional que considera as especificidades de alunos jovens e adultos, assim como as características desta modalidade de ensino, onde se destacam alguns princípios:

\footnotetext{
${ }^{4}$ Esta proposta curricular foi elaborada pela Coordenação Geral de Educação de Jovens e Adultos COEJA, para atender à demanda de dirigentes e professores de diversas regiões de nosso país e está organizada em três volumes. O volume 1 apresenta, em duas partes, temas que devem ser analisados e discutidos coletivamente pelas equipes escolares, pois trazem fundamentos comuns às diversas áreas para a reflexão curricular. A SECAD sugere a leitura do documento introdutório desta coleção, para compreender melhor os documentos dos volumes 2 e 3 . Disponível em: $<$ http://portal.mec.gov.br/secad/arquivos/pdf/eja_livro_01.pdf >. Acesso em: 27 jan 2012.

${ }^{5}$ Grifo da autora. Olh@res, Guarulhos, v. 2, n. 2, p. 449-470. Dezembro, 2014.
} 
- a necessidade de unir esforços entre as diferentes instâncias governamentais e da sociedade, para apoiar a escola na complexa tarefa educativa;

- o exercício de uma prática escolar comprometida com a interdependência escola/sociedade, tendo como objetivo situar os alunos como participantes da sociedade (cidadãos);

- a participação da comunidade na escola, de modo que o conhecimento aprendido resulte em maior compreensão, integração e inserção no mundo;

- a importância de que cada escola tenha clareza quanto ao seu projeto educativo, para que, de fato, possa se constituir em uma unidade com maior grau de autonomia e que todos os que dela fazem parte possam estar comprometidos em atingir as metas a que se propuseram;

- o fato de que os jovens e adultos deste país precisam construir diferentes capacidades e que a apropriação de conhecimentos socialmente elaborados é base para a construção da cidadania e de sua identidade;

- a certeza de que todos são capazes de aprender. (BRASIL, 2002a, p. 7)

O problema está em garantir que estes princípios sejam efetivados na prática, o que só irá se concretizar quando houver uma conscientização sobre a importância de se conhecer os documentos oficiais que regulamentam a educação de jovens e adultos.

Sendo assim, parece fundamental que os professores da EJA estejam atentos à sua autoformação, no que se refere ao entendimento das leis que definem e conceituam a modalidade na qual lecionam, e à sua formação continuada, no que se refere a preencher as lacunas deixadas pela formação inicial.

\section{Práticas na instituição}

As práticas de colaboração dos professores têm sido apontadas como um dos aspectos mais importantes de uma nova cultura dos professores (PONTE e SERAZINA, 2004). Embora mereçam destaque nas análises sobre as práticas não letivas na instituição, no estudo realizado, detectei que os professores participantes não trabalhavam de forma colaborativa. Todavia, acredito na colaboração como uma estratégia de trabalho bastante adequada para lidar com as 
diversas questões surgidas no cotidiano dos ambientes escolares e na vida dos sujeitos que deles participam.

Apesar de um ambiente amigável e do clima de coleguismo entre professores, funcionários e direção, notei a ausência de colaboração na preparação e na realização de projetos educativos e na reflexão sobre as práticas letivas. Provavelmente, todos se beneficiariam trabalhando em conjunto. Mas, como nem todos pensam assim, os encontros informais acabam sendo mais frequentes do que os trabalhos formais e organizados em grupo. Assim, pareceu prevalecer entre os professores pesquisados uma prática não colaborativa e uma cultura profissional "marcada pelo individualismo" (PONTE e MENEZES, 2009, p. 3).

Como as práticas não letivas na instituição não se resumem às práticas de colaboração tentei observar também de que modo os professores participam de reuniões e conselhos de classe, sua maneira de agir perante os procedimentos oficiais reguladores da atividade pedagógica e suas responsabilidades em relação às questões oficiais. Essas práticas dizem respeito também aos movimentos associativos e a disponibilidade para participar de pesquisas.

Durante o período correspondente à realização da pesquisa de campo, foram agendados dois conselhos de classe. O conselho de classe é uma boa oportunidade para os professores conhecerem melhor os alunos e as atitudes destes em relação às outras matérias e aos outros professores. Considerando isso, os professores pesquisados informaram que participavam, sempre que possível, dos conselhos de classe. Nessas ocasiões, realizavam um levantamento do caminho percorrido pelo aluno e procuravam saber quais seriam as expectativas futuras destes educandos. Pude verificar o resultado desta prática não letiva nas entrevistas realizadas com os professores Eva, Mara e Jair. Os três professores afirmaram conhecer bem "seus" alunos buscando ajudá-los enquanto estudantes daquela instituição. Sobre isto, a direção da escola confirmou que "os professores daqui têm um cuidado, uma atenção, um carinho especial com os alunos que 
é difícil de ver por aí", reconhecendo a importância desta postura nos professores de matemática.

Os professores deste estudo de caso eram, simultaneamente, matemáticos, educadores e funcionários públicos. Como funcionários públicos, estavam obrigados a cumprir os procedimentos e as determinações impostas pelo órgão regulador da sua atividade profissional corretamente. Porém, nem sempre esta fiscalização era feita de forma adequada, acarretando certo descontentamento nos professores em relação aos supervisores escolares. Para Eva, essas intromissões costumam ser improdutivas.

Presenciei uma destas visitas de fiscalização escolar exatamente no dia em que estava entrevistando a professora Eva. Vimos que o encarregado pela supervisão estava conferindo uns documentos na secretaria. Eva apontou para ele e comentou:

Professora Eva: - Vira e mexe tem gente aqui, que é supervisor não sei do quê, não sei do quê lá... Toda hora troca, a cada 6 meses ou um ano, troca. Tem várias pessoas, esse aí não é o único que vem. Então essas pessoas se acham no direito de palpitar... e pronto!

Pesquisadora: -São fiscais da secretaria?

Professora Eva: - É... e ele recebe ordens também. Até que esse agora é tranquilo. Mas tivemos um extremamente arrogante, que chegou a agredir verbalmente a gente. Ele marcou uma reunião de forma muito agressiva. Falou que, encurtando, quem não obedecesse, quem não seguisse ao pé da letra tudo o que ele estava falando, de repente podia cair numa escola lá na Vila do João, lá na Avenida Brasil... Que nós não éramos professores daqui, e sim do estado. Então, a gente podia ser remanejado. Começou a ameaçar e ameaçar! De uma forma muito estúpida, muito estúpida! Cada vez que este senhor vinha, eu fazia questão de sair do ambiente onde ele estava. Eu não frequentava as reuniões dele. (...) Ele foi transferido, sumiu.

Pesquisadora: -Ele era contratado para quê?

Professora Eva: - Ele vinha fiscalizar a escola, fazer relatórios dizendo que os alunos não estavam devidamente uniformizados, sei lá, de um monte de coisas, regras que não cabiam a ele.

Em outros momentos, os professores eram convocados a preencher formulários enviados pela SEEDUC sobre os mais diversos assuntos. Desta forma, se questionam sobre a utilidade desses controles burocráticos que não resultavam em ações na prática, Olh@res, Guarulhos, v. 2, n. 2, p. 449-470. Dezembro, 2014. 
conforme bem situou Mara dizendo que "é totalmente inútil e ninguém fica sabendo o que eles fazem com tanto papel”. Lembro que, quando entreguei o questionário final desta pesquisa para $o$ professor Jair responder, ele aproveitou para compará-lo aos questionários da secretaria. Até porque, conforme sinalizou, ele "não se incomodaria de preencher se depois houvesse um retorno sobre essas ações do governo". Contudo, em relação a colaborar com a pesquisa em questão, o professor Jair comentou:

Vou responder com todo o prazer. Eu acredito na pesquisa. Sei que na área da educação as mudanças são lentas, demoram a ser implementadas. Os professores precisam, precisam não, têm obrigação de denunciar o que veem de errado. Com a ajuda de vocês, das pesquisas de vocês, a situação pode ir melhorando pra todos os lados. Quem sabe?

Esta disponibilidade para participar da pesquisa esteve presente também na postura colaborativa das professoras Eva e Mara. No cotidiano desta investigação, as práticas não letivas na instituição foram sutilmente surgindo e sendo indiretamente percebidas até se constituírem em objetos passíveis de análise.

Numa determinada ocasião, os alunos e docentes foram convidados a assistir uma peça de teatro e, como também havia sido convidada, aproveitei para observar e compreender melhor esta prática profissional no cotidiano daqueles sujeitos. Não houve nenhum tipo de prática letiva antes, durante e depois do passeio cultural, que envolvesse os sujeitos observados. Sendo assim, considerei a ida ao teatro como uma prática não letiva, já que a atividade não foi planejada pelos professores envolvidos, nem teve a intenção de concretizar a relação ensino aprendizagem com e para o aluno da EJA. Entretanto, durante o passeio cultural, acredito que cada um aproveitou a situação de uma forma diferente, ora ensinando, ora aprendendo alguma coisa naquele dia.

Afirmar simplesmente que a ida ao teatro era uma prática não letiva me pareceu, de certa forma, imprudente. Para redimir esta dúvida, recorri às considerações de Carbonell (2010, p. 40) que acredita nas saídas com alunos como excelentes meios para intensificar suas relações com os colegas e, sobretudo, "apropriar-se Olh@res, Guarulhos, v. 2, n. 2, p. 449-470. Dezembro, 2014. 
dos bens culturais da cidade onde residem, convertendo-se em um conduto para a inclusão cultural dessas pessoas". Ainda segundo a autora:

Levar os alunos jovens e adultos a museus, galerias, centros de cultura, teatros, feiras, praças e eventos culturais é essencial para a apreciação da arte na sua forma genuína, viva, original, além de ser um excelente meio para estimular a frequentação autônoma e o retorno a esses locais. Percorrer as salas de um museu, ouvir um concerto, assistir a um espetáculo de teatro, sentar-se em um banco de praça para conversar sobre a escultura que nunca recebera a devida atenção são atividades que abrem caminhos para a fruição e o prazer que o contato com a arte pode proporcionar. (CARBONELL, 2010, p. 40)

Os alunos da EJA dificilmente visitam esses locais a não ser através de uma mediação da escola. Enquanto justificou a importância destes eventos como possibilidades de transcender as quatro paredes da sala de aula, a autora sinalizou que estas saídas estão imbuídas de valores não somente culturais, mas também sociais e de lazer. Para Bourdieu,

A função da escola consiste em desenvolver ou criar as disposições para a cultura, atuando como suporte de uma prática cultural duradoura e intensa. A instituição deveria, pelo menos em parte, compensar a desvantagem daqueles sujeitos que não encontram, em seu meio familiar, incitação às práticas sociais que cultivem a apreciação da arte. (BOURDIEU apud CARBONELL, 2010, p. 44)

Lembrando que uma prática não letiva ocorre quando não se tem a intenção de ensinar algo diretamente ao aluno, considerei a ida ao teatro como uma prática não letiva de autoformação cultural. Prática esta que deveria ser mais frequente, visto que abarca tanto os professores quanto os alunos. No entanto, os saberes adquiridos através desta prática só farão sentido aos alunos quando estiverem em consonância com o projeto político pedagógico da escola. Para Carbonell (2010, p. 45) isto significa uma prática “com objetivos mais amplos que capacitam o adulto a dominar novas tecnologias, a trabalhar em equipe, a expressar-se com segurança na língua materna, a desenvolver seu espírito crítico e sua consciência cidadã". 
Encerrando a análise das práticas de formação e das práticas na instituição, parece fundamental que os professores da EJA, além de estarem atentos à sua autoformação e à sua formação continuada, possam se mobilizar no sentido de colaborar entre si e com grupos de pesquisa, participar de sindicatos, conhecer as leis que regem a docência na rede pública e frequentar reuniões e conselhos de classe. Estas práticas não letivas estarão influenciando diretamente suas práticas letivas e esta atitude parece ser fundamental para que o exercício das práticas profissionais destes professores de matemática da EJA esteja coerente com a proposta de ensino democrático, laico e de qualidade que a sociedade tanto espera.

Conclusões provisórias: porque não precisamos do fim para chegar

Sobre as práticas não letivas, as primeiras conclusões provisórias deste recorte de pesquisa dizem respeito às concepções da EJA reveladas pelos professores participantes. Eva, Mara e Jair têm opiniões parecidas quanto à finalidade da EJA como uma oportunidade. Suas concepções em relação às funções reparadora, equalizadora e qualificadora da EJA, mesmo que intuitivas, poderiam ser mais bem compartilhadas caso eles assumissem uma postura colaborativa em suas práticas profissionais.

Durante o caminho percorrido ficou evidente que, apesar de não possuir uma ligação direta com o processo de ensino aprendizagem, as práticas não letivas influenciam o modo como os professores constroem e desenvolvem suas práticas profissionais. Principalmente, aquelas relacionadas à sua formação continuada. Ao supor que aprendem a lecionar na EJA com as situações típicas do diaa-dia, os professores estão na verdade validando um percurso profissional solitário, normalmente marcado por situações repetitivas. Por isso, a falta de formação do professor para lecionar na EJA, pode ser um dos principais motivos para o fracasso na constituição de uma equipe comprometida com o destino de todos os seus alunos. Olh@res, Guarulhos, v. 2, n. 2, p. 449-470. Dezembro, 2014. 
Existem alternativas capazes de abranger boa parte da problemática da educação de pessoas jovens e adultas e uma delas é o investimento político e financeiro do governo, tanto no estabelecimento de prioridades educacionais legítimas como em forma de recursos concretos. Para oferecer ensino de qualidade a todos os educandos jovens e adultos, a formação inicial ou continuada do professor, necessita ser reconsiderada em caráter de urgência.

Com relação às práticas na instituição, percebi que os professores Eva, Mara e Jair desconhecem as leis e regulamentos. Os sistemas de controle e fiscalização da instituição são vistos pelos professores como ações inúteis e burocráticas. Por isso, não tinham credibilidade dos professores, que apenas cumprem as exigências do sistema sem esperar um retorno do governo sobre essas ações. Por outro lado, a postura colaborativa em relação a esta investigação permaneceu durante todo o período em que estive realizando a pesquisa de campo.

Por outro lado, não presenciei os professores participando de associações ou envolvidos com sindicatos de classe, muito menos preocupados em conhecer as políticas públicas relacionadas à profissão docente. Os conselhos de classe eram as únicas reuniões agendadas as quais os professores compareciam, mais por obrigação do que com intenção de analisar a relação ensino aprendizagem desenvolvida no período, como parte da prática docente. Assim como não havia reunião para elaborar o planejamento anual, também não havia reunião para ajustar o projeto político pedagógico, que não sofria alterações há anos.

Neste cenário, acredito que os questionamentos que nortearam esta pesquisa, foram sendo respondidos durante a análise dos dados obtidos no campo e da interpretação das observações realizadas. No geral, o estudo de caso realizado buscou entender os "comos" e os "porquês" inerentes às práticas não letivas dos professores de matemática sujeitos da pesquisa. Neste sentido, o caminho traçado, o percurso estabelecido, o trajeto instituído, continuarão provisórios, 
Professores de matemática da EJA: um estudo sobre suas práticas não letivas

pois "um estudo de caso nunca está completo, sendo sempre possível acrescentar-lhe mais qualquer coisa" (PONTE, 2006, p. 7).

Olh@res, Guarulhos, v. 2, n. 2, p. 449-470. Dezembro, 2014. 


\section{Referências bibliográficas}

ARROYO, M. G. Educação de jovens e adultos: um campo de direitos e responsabilidade pública. In:SOARES, L.; GIOVANETTI, M. A.; GOMES, N. L. (orgs). Diálogos na educação de jovens e adultos. 2 ed. Belo Horizonte: Editora Autêntica, 2007. 296 p. cap. 1, p. 19-50.

BOGDAN, R. C.; BIKLEN, S. K. Investigação qualitativa em educação: uma introdução à teoria e aos métodos. 2 ed. Portugal: Porto Editora, 1994. 335 p. (Coleção Ciências da Educação)

BOURDIEU, P.; DARBEL, A. O amor pela arte. São Paulo: Edusp, 2003.

BRASIL. Ministério da Educação. Parecer CNE/CEB 11/2000. Diretrizes curriculares nacionais para Educação de Jovens e Adultos. Brasília: MEC, 2000.

- Ministério da Educação. SECAD/COEJA. Proposta curricular para o segundo segmento da educação de jovens e adultos. Brasília: MEC, 2002a. 146 p. v. 1. - Ministério da Educação. SECAD/COEJA. Proposta curricular para o segundo segmento da educação de jovens e adultos. Brasília: MEC, 2002b. 66 p. v. 3 BRUNELli, O. A.; DARSIE, M. M. P. Formação de Professores de Educação de Jovens e Adultos. In: Conferência Interamericana de Educação Matemática. 13., 2011, Recife. Anais... Recife: UFPE, 2011. 1 CD-ROM.

CARBONELL, S. Educação estética para jovens e adultos: a beleza no ensinar e no aprender. São Paulo: Cortez. 2010. 128 p. (Coleção Questões de Nossa Época, v. 10)

COROA, R. P. Saberes construídos pelos professores de Matemática em sua prática docente na Educação de Jovens e Adultos. Belém, 2006.107 f. Dissertação (Mestrado em Ciências e Matemática) - Universidade Federal do Pará, Belém, 2006.

FANTINATO, M. C. C. B; et al. O Programa Etnomatemática como Humanizador do Ensino de Matemática In: Conferência Interamericana de Educação Matemática. 13., 2011, Recife. Anais... Recife: UFPE, 2011. 1 CD-ROM.

FONSECA, M. C. F. R. Educação Matemática de Jovens e Adultos: especificidades, desafios e contribuições. 2 ed. rev. Belo Horizonte: Autêntica, 2005. 120 p. (Coleção Tendências em Educação Matemática).

Olh@res, Guarulhos, v. 2, n. 2, p. 449-470. Dezembro, 2014. 
FIORENTINI, D. Formação de professores a partir da vivência e da análise de práticas exploratório-investigativas e problematizadoras de ensinar e aprender Matemática. In: Conferência Interamericana de Educação Matemática. 13., 2011, Recife. Anais... Recife: UFPE, 2011. 1 CD-ROM.

FREIRE, P. Pedagogia da Autonomia: saberes necessários à prática educativa. São Paulo: Paz e Terra. 1996. 148 p.

GILS, A. L. Contribuições da etnomatemática para a Educação de Jovens e Adultos e para a formação de professores. Niterói, 2010. 170 f. Dissertação (Mestrado em Educação) - Universidade Federal Fluminense, Niterói, 2010.

LOPES, L. R. P. Formação do professor de Matemática "para" e "na" EJA Educação de Jovens e Adultos. Uberaba, 2009. 172 p. Dissertação (Mestrado em Educação) - Universidade de Uberaba, Uberaba, 2009.

LÜDKE, M.; ANDRÉ, E. D. A. M. Pesquisa em educação: abordagens qualitativas. São Paulo: EPU, 1986. 99 p.

PONTE, J. P. Estudos de caso em Educação Matemática. Bolema, n. 25. 2006.p.105132. Disponível em: <http://repositorio.ul.pt/>. Acesso em: 16 fev 2012.

.Prácticas profesionales de los profesores de matemática. In: Conferência no CINVESTAV Departamento de Matemática Educativa, 2011. México: Centro de Investigación y de Estudios Avanzados del Instituto Politécnico Nacional.

; MENEZES L. Investigação colaborativa de professores e ensino da Matemática: caminhos para o desenvolvimento profissional. Jornal Internacional de Estudos em Educação Matemática, n. 1(1). 2009.

; QUARESMA, M.; BRANCO, N. Práticas profissionais dos professores de Matemática. Revista Avances en Investigación en Educación Matemática. 2008.

; SERRAZINA, M. L. Práticas profissionais dos professores de Matemática. Quadrante - Revista Teórica e de Investigação, Lisboa: Associação de Professores de Matemática, n. 13(2), p. 51-74, 2004.

VENTURA, J. P. Educação de Jovens e Adultos ou educação da classe trabalhadora? Concepções em disputa na contemporaneidade brasileira. Niterói, 2008. 302 f. Tese (Doutorado em Educação) - Faculdade de Educação, Universidade Federal Fluminense, Niterói, 2008.

Olh@res, Guarulhos, v. 2, n. 2, p. 449-470. Dezembro, 2014. 